\title{
CIÊNCIA E MATEMÁTICA, NA REPÚBLICA, DE PLATÃo
}

\author{
Hugo Filgueiras de Araújo*
}

\section{Resumo}

O presente trabalho tem o intuito de entender como Platão na República aborda os conceitos de matemática e ciência, mais especificamente nos livros V, VI e VII desse diálogo. Primeiramente foram levantadas algumas questões consideradas preliminares em relação ao modo peculiar com o qual Platão desenvolveu sua escrita, no caso o estilo dialógico que pede todo um cuidado em sua leitura, como também levantou-se a problemática das traduções feitas do grego para o português que, por vezes, dificulta seu entendimento. Em um segundo momento foi abordado o entendimento do termo ciência nos gregos, fazendo uma relação com a matemática. Como ponto de partida, foi tomado o pressuposto de que para Platão a matemática não se enquadra na classificação de ciência. Busca-se nessa pesquisa entender estes conceitos na filosofia platônica, e não há como realizar tal propósito sem lançar mão das questões que mais são relevantes na filosofia platônica (epistemologia e ontologia), tomando mão dos argumentos da Reminiscência e da Teoria das Formas. O trabalho termina por concluir que ciência só é considerada na filosofia platônica aquela que pode ter o conhecimento da realidade, e essa, segundo o filósofo, é a dialética; ficando a matemática, por conseguinte, enquadrada dentro de um âmbito do conhecimento que Platão na República diz estar entre a opinião (doxa) e a própria ciência (epistême) que é o entendimento (dianóia).

Palavras-chave: Platão. Dialética. Ciência. Matemática.

\begin{abstract}
This article aims to analyze how the Republic of the Plato discusses the concepts of math and science, more specifically in books V, VI and VII of this dialogue. Were first raised some preliminary issues considered in relation to the peculiar way in which Plato developed his writing, if the dialogical style that asks a whole care in their reading, but also arose the problem of translations made from Greek to Portuguese that sometimes hinders its understanding. In a second moment was approached understanding of the term science in Greek, making a relationship with mathematics. As a starting point, was taken the assumption that for Plato the math does not fit the classification of science. This research seeks to understand these concepts in the Platonic philosophy, and there is no way to accomplish such a purpose without resorting to the issues that are most relevant in the Platonic philosophy (epistemology and ontology), considering the arguments of Reminiscence and the Theory of Forms. The paper ends by concluding that science is only considered in the Platonic philosophy that we can have knowledge of the reality, and that, according to the philosopher, is the dialectic; getting the math therefore framed within a framework of knowledge that Plato says in the Republic be among the opinion (doxa) and science itself (epistême) that is the understanding (dianoia).
\end{abstract}

\footnotetext{
* Doutor em Filosofia pela Universidade Federal da Paraíba e Professor Adjunto do Curso de Filosofia da Universidade Federal do Ceará. E-mail: hugofilguaraujo@hotmail.com. CV: http://lattes.cnpq.br/9236980688564628.
}

DIALEKTIKÉ, v. 1, novembro 2014, p. 89-96

Artigo submetido em setembro/2014 e aceito em outubro/2014 
Key words: Plato. Dialectic. Science. Mathematics.

\section{INTRODUÇÃO}

Há um caráter todo peculiar na filosofia platônica, por ser considerada uma das de maior dificuldade de entendimento, devido à diversidade de temas tratados por Platão, como também da forma como ele escreve. Platão escreve diferentemente dos outros filósofos, não fez "tratados filosóficos" e sim "diálogos", nos quais de forma toda especial, no caso com o discurso dialético, trabalha a construção de conceitos. Por esse motivo, a leitura dos seus textos deve ser feita percebendo o todo de sua obra, não só no diálogo que se tem por objeto de estudo, mas também considerando outros que venham a ajudar no entendimento de sua 'doutrina' ${ }^{1}$. Um outro fator relevante para a leitura e entendimento de sua filosofia é o caráter cultural, sobretudo a língua grega, no grego há palavras que sendo traduzidas para as línguas modernas não se consegue abarcar todo o seu significado.

Entender conceitos dentro da filosofia platônica requer este duplo cuidado: de levar em consideração o caráter dialógico de seus escritos, como também a complexidade da língua e cultura gregas.

\section{A CIÊNCIA PARA OS GREGOS}

Os livros V, VI e VII da República diante de outros temas, vem retratar com Glauco e Sócrates a busca do entendimento do que seja a matemática. No passo 533d, Sócrates afirma que o método dialético é o único que se enquadra como ciência, assim descarta a matemática, como também as outras modalidades do saber, dessa classificação:

Assim, continuei, o método dialético é o único que rejeita as hipóteses para atingir diretamente o princípio e consolidar suas conclusões, e que puxa brandamente o olho da alma do lamaçal bárbaro em que vivia atolado, a fim de dirigi-lo para cima, empregando para essa conversação as mencionadas artes, como auxiliares e cooperadoras.

\footnotetext{
1 "Há que atender a dois aspectos contraditórios na interpretação dos diálogos: a) Platão não escreveu "tratados" de filosofia, pelo que é difícil saber, em tudo o que diz, que parte corresponde ao seu pensamento; b) os diálogos não podem porém, ser encarados como se fossem meras histórias, representações teatrais". SANTOS, José Trindade. Fédon, de Platão. Apartado: Alda, 1998 pg. 16 Nota 04.
}

DIALEKTIKÉ, v. 1, novembro 2014, p. 89-96

Artigo submetido em setembro/2014 e aceito em outubro/2014 
Partindo desse ponto, pode-se perguntar: Quais os motivos que fazem com que Platão não considere a matemática como ciência e só a dialética?

Pode-se perceber três pontos que necessitam ser entendidos, dentro do que Platão trabalha na República, para embasar esse não enquadramento da matemática como ciência: 1) O que é ciência e matemática para os gregos e em Platão 2) Qual o objeto de estudo da ciência e da matemática 3) Quais as condições para que uma atividade humana seja considerada uma ciência para Platão.

Talvez soe-nos de forma estranha dizer que matemática não é ciência, contudo devese considerar que essa noção é própria da filosofia platônica. A priori é mister perceber que o termo "ciência" para os gregos, e conseqüentemente em Platão, não tem o mesmo significado que tem para nós hoje, o sentido hodierno de ciência é o que os gregos chamavam de teckné. Segundo Gadamer "[...] lo que nós designamos com o conceito usual de ciência foi entendido pelos gregos, sobretudo, como o saber daquilo cuja base é possível fabricar algo: o chamavam poietike episteme o techne"2, exemplo era a medicina que pelos gregos era chamada arte de cura; esse fato faz perceber a importância de especificar que não se pode empregar conceitos sem antes ter idéia do contexto cultural do tempo em que a obra foi escrita, ou o pensador viveu, e mais se tratando ainda de Platão que tinha uma concepção própria do que seja ciência. Para Platão, o conceito da ciência (epistêmê) está vinculado ao de conhecimento (gnosis). Para o Filósofo, ciência é o que permite chegar ao conhecimento, e conhecer é buscar a verdade, a verdade das coisas em si.

\section{CONHECIMENTO E CIÊNCIA EM PLATÃO - REMINISCÊNCIA}

No pensamento platônico, conhecer é uma recordação, aprender é recordar ${ }^{3}$. Conhecer é reminiscência, é recordar-se de algo com o qual um dia o homem já teve contato. O estatuto da reminiscência apregoa-se na crença na imortalidade da alma ( $p s y k h e ́$,$) , que antes$ do nascimento (encarnação) já existia, e neste tempo de existência anterior ao nascimento teria tido contato com as Formas inteligíveis; logo, tudo que na vida terrena é conhecido pela

\footnotetext{
${ }^{2} C f$. GADAMER, Hans-Georg. Acerca do filosófico nas ciências e do científico na filosofia. IN: A razão na época da Ciência. Rio de Janeiro: Edições Tempo Brasileiro, 1983, pp. 14.

3 “Aprender... não é outra coisa senão recordar”. (Fédon 73e).
}

DIALEKTIKÉ, v. 1, novembro 2014, p. 89-96

Artigo submetido em setembro/2014 e aceito em outubro/2014 
razão, na verdade é relembrado pela alma ${ }^{4}$. A Forma seria o objeto do conhecimento (epistêmê). A Forma em Platão, é aquilo que sempre é, aquilo que é imutável e perfeito, é uno, é a essência das coisas, é o ser. Neste sentido, na República em 476d, Sócrates afirma a Glauco que o conhecimento só pode se dar daquilo que é e que existe em si mesmo, fora disso não pode haver conhecimento e ou ciência.

Para Platão há coisas belas e a Beleza em si, coisas boas e o Bem em si. O conhecimento se dá não das coisas belas e boas, mas da Beleza e do Bem, estas últimas sendo a Forma com a qual a alma teve contato e que, pela razão, através do contato com os sensíveis, tem a recordação. No passo 477a, Sócrates questiona Glauco acerca do que pode ser conhecido e chega à conclusão de que só o que existe é objeto do conhecimento, o que não existe não se enquadra como algo passível de conhecer; em outras palavras, conclui que o conhecimento se dá do que é (o ser) e não se pode conhecer aquilo que não é (não-ser).

Sabemos, portanto, com segurança acima de toda exceção, seja qual for o aspecto por que estudemos o problema, que o que tem existência perfeita é perfeitamente conhecível, e que não podemos conhecer o que não existe de maneira nenhuma.

Sócrates vem apresentar duas faculdades que respectivamente estarão voltadas para o ser e o não-ser: o conhecimento corresponde ao ser e a ignorância corresponde ao não-ser. $\mathrm{O}$ filósofo, ainda em 477a, abre uma nova possibilidade, uma via intermediária entre o conhecimento e a ignorância, visto que há coisas que nem estão no âmbito do que é em si e nem do que não é, do ser e do não-ser: a aparência $^{5}$, e a esta compete a opinião (doxa). A opinião, no passo 477b, é diferente do conhecimento porque não se relaciona com o ser por natureza, e assim não gera conhecimento (conhecimento só se tem do ser em si, das Formas), também é diferente da ignorância, porque o não-ser sequer pode ser conhecido (478b). Em 508d Glauco e Sócrates concordam que opinião e ciência são diferentes faculdades. O conhecimento conhece o ser em si, a ignorância é o não-conhecimento do não-ser e à opinião caberia conjecturar, emitir uma posição a partir daquilo que lhe aparenta. Nesses passos,

\footnotetext{
${ }^{4} \mathrm{O}$ estatuto da reminiscência e da imortalidade da alma são tratados de forma específica no diálogo platônico Fédon.

${ }^{5}$ A aparência se dá a partir do contato com as coisas sensíveis, que diferentemente das formas que são são unas, são múltiplas. As coisas sensíveis permitem a conjecturação e a emissão de opiniões diversas, isso porque ao algo belo comparado com um mais belo é considerado feio, e comparado com um menos belo, é considerado mais belo.
}

DIALEKTIKÉ, v. 1, novembro 2014, p. 89-96

Artigo submetido em setembro/2014 e aceito em outubro/2014 
encontra-se mais uma vez a tensão existente entre as duas realidades que nos escritos platônicos são constantes, entre as coisas sensíveis e as Formas inteligíveis.

\section{A MATEMÁTICA E A OPINIÃO}

Tendo aberto a possibilidade da existência de três faculdades: conhecimento, ignorância e opinião, resta-nos perceber por que Platão não enquadra a matemática na categoria de ciência e sim somente a dialética, e não enquadrando como ciência, onde ele enfim, posiciona a matemática. Para Platão ciência só é a dialética, ciência está voltada à busca do saber, à perfeição do conhecimento que só as formas podem dar, a dialética é que oferece, segundo seu pensamento, essa função ${ }^{6}$.

A matemática para ser enquadrada como ciência por Platão, necessitava que seu objeto fosse considerado com caráter de Forma. Segundo Maclarty, Platão não considerava os objetos matemáticos com esse caráter ${ }^{7}$, para ele objetos matemáticos não são perfeitamente reais. Há controvérsias no entendimento e até uma discordância em afirmar que Platão no passo 527b punha na boca de Sócrates uma contradição, em dizer que a geometria (instância da matemática) é o conhecimento do que sempre é, se assim Sócrates tivesse falado, a geometria e conseqüentemente a matemática seria vista sim por Platão como uma ciência, pois para este, ciência é o conhecimento do ser, da Forma. Mueller e Vlastos perceberam que tal afirmação na República foi feita não por Sócrates, mas sim por Glauco, em contrapartida Shapiro defendia que fora Sócrates, para defender sua posição de que para Platão os objetos matemáticos são eternos ${ }^{8}$.

Outro ponto em questão que explica a não classificação da matemática por Platão com ciência, está no fato dela ser elaborada em cima de hipóteses.

Em geral artes se ocupam com as opiniões e os gostos dos homens e seus respectivos processos de formação e fabricação, ou cuidam dos produtos naturais ou artificiais. As demais que conforme admitimos, de algum modo apreendem o verdadeiro ser, a Geometria e ciências correlatas, vemos como a respeito do ser o que fazem é sonhar, sem que no estado de vigília consigam contemplá-lo, por só recorrerem a hipóteses, em que não tocam por não saberem fundamentá-las. Ora, quando o princípio é feito de não sei o quê, e o meio e o fim da mesma coisa, que não sabe se sabe bem o que seja,

\footnotetext{
${ }^{6}$ Cf. MACLARTY, Colin. Platonismo Matemático versus Recolher os Mortos: 0 que Sócrates ensina a Glauco. Pg. 03

${ }^{7}$ Ibidem. Pg. 04

${ }^{8}$ Ibidem.Cf. Nota 17
}

DIALEKTIKÉ, v. 1, novembro 2014, p. 89-96

Artigo submetido em setembro/2014 e aceito em outubro/2014 
de que modo o que foi concebido desse jeito chegará a construir alguma ciência? (República, 533bc)

Hipóteses remetem-se a opiniões, que podem ser verdadeiras ou não (533d), e de algo que é perfeito e é em si não se pode tecer uma opinião falsa, o que já descarta a identificação com as Formas; contudo, o método dialético é o único que as rejeita, mais uma vez Sócrates toma a dialética como referência de ciência, por esta atingir o princípio em si, a Forma.

A matemática, segundo Platão, usa de hipóteses, pois "toma as coisas como se as conhecessem", , contudo mesmo havendo essa relação entre hipótese e opinião, enquadrá-la diretamente como faculdade da opinião seria problemático, pois na matemática se faz uso do raciocínio e não só dos sentidos (511d). Daí pergunta-se: Onde está enquadrada a matemática? Mais à frente na República, precisamente em 511d, Platão vem dar à atividade dos geômetras (matemáticos) o nome de entendimento (dianóia), pois este seria um intermediário entre a opinião e a razão.

Um outro aspecto a ser analisado é quanto à natureza dos objetos matemáticos, estes não são perfeitamente reais e nem são inexistentes, pois estão também na via intermediária entre o conhecimento e a ignorância, logo expressam uma característica da aparência. $\mathrm{O}$ caráter da identidade dos objetos matemáticos é o que não permite a classificação da matemática como ciência: estes não são o que sempre é, ou seja, não são Formas.

Com os argumentos expostos até então, torna-se claro que para Platão a matemática não é considerada ciência; porém isto não significa que por parte do mesmo haja um certo desprezo pela matemática, em detrimento da dialética. A leitura de Platão é tensa, devido às dicotomias: ser e não-ser, sensação e razão, corpo e alma etc; leituras mais fundamentalistas conseguem radicalizar Platão atribuindo a ele uma postura de enaltecer o Inteligível e desprezar o sensível, mas é mister perceber que ele não despreza uma instância em detrimento da outra, há sim um certo privilegiamento da razão, da Forma e da alma, mas sem deixar de perceber a participação da sensação, das coisas sensíveis e do corpo no processo de cognição.

\section{A MATEMÁTICA CONDUZ AO CONHECIMENTO DAS FORMAS}

\footnotetext{
${ }^{9}$ Afirmação proferida na aula do Prof. Giovanni Queiroz, na disciplina de Metafísica do Mestrado em Filosofia na UFPB, dia 03 de agosto de 2007.
}

DIALEKTIKÉ, v. 1, novembro 2014, p. 89-96

Artigo submetido em setembro/2014 e aceito em outubro/2014 
A leitura que Maclarty faz do que Platão entende pela interação entre matemática e ciência no intercâmbio e na relação com seus respectivos objetos, expõe que "os objetos matemáticos incita-nos às Formas, mesmo sem existirem como Formas"10. Retomando o estatuto da reminiscência, no Fédon (74c, 75a, 75b, 75e e 75e-76a) Platão estabelece uma certa relação de participação entre a sensação e a razão no processo cognitivo, o contato com a Forma é anterior à senso-percepção, isto na pré-existência da alma, mas é a partir do contato com as coisas sensíveis (com o semelhante e o dessemelhante, na vida encarnada) que se tem a recordação das Formas inteligíveis, em outros termos, é pelo contato com as coisas belas que se pode relembrar a Beleza em $\mathrm{si}^{11}$; esse mesmo argumento pode ser empregado à matemática, os objetos matemáticos conduzem ao conhecimento das Formas. Ainda no diálogo Teeteto $^{12}$, há um verdadeiro discurso sobre a opinião como participante no processo de conhecer, Sócrates nesse diálogo chega a questionar seus interlocutores (Teodoro e Teeteto) se poderia considerar a opinião verdadeira como pensamento verdadeiro e a opinião falsa como ignorância (Teeteto, 170bc), nesse diálogo a opinião é valorizada no processo da aquisição do saber, quando emitida de forma verdadeira, gera conhecimento.

No passo 531a da República, Sócrates diz que a dialética é uma canção para aprender depois da matemática ${ }^{13}$, ou seja, a matemática é via, ela não alcança a Forma, só a dialética o faz, contudo contribui para a aquisição do saber. Ela empurra a alma para a verdade, para o conhecimento das realidades em si. Enquanto a dialética busca o conhecimento do ser em si, a geometria permite a produção de pensamento filosófico, ajuda a voltar para o ser, mas não permite o conhecimento do que sempre é. A geometria (matemática) produz pensamento (dianóia) e não conhecimento (epistêmê). Logo a matemática para Platão mesmo não sendo ciência, tem sua importância e parcela no processo cognitivo.

\section{CONCLUSÃO}

\footnotetext{
${ }^{10} \mathrm{Cf}$. MACLARTY, pg. 03

11 "Definido o princípio segundo o qual só pode haver reminiscência daquilo que antes se "soubera" epistasthai: 73c), a comparação dos iguais sensíveis com o Igual estabelece a prioridade cronológica (74e-75e), psicológica (74c-d) e epistemológica (74d-75d) do inteligível sobre toda a experiência sensível. Todavia, além das referências indirectas, o argumento insiste repetidamente (74c, 75a, b, e, 75e-76a) no facto de ser através da sensibilidade que "recuperamos" (analambanomen: 75e) este saber. É na natureza desta "recuperação" que se acha a sua maior subtileza". SANTOS, José Trindade. A função da alma na percepção, nos diálogos platónicos. Lisboa, Brasília e S. Paulo 2004. Pg. 2

${ }^{12} \mathrm{O}$ Teeteto é um dos diálogos platônicos que não trata diretamente das formas inteligíveis, garantindo assim a segurança na leitura de que Platão realmente não despreza a sensação na aquisição do saber, sabendo dar-lhe sua devida importância.

${ }^{13} C f$. MACLARTY, pg. 09
}

DIALEKTIKÉ, v. 1, novembro 2014, p. 89-96

Artigo submetido em setembro/2014 e aceito em outubro/2014 
O caminho percorrido nos fez perceber que tanto na cultura grega como em Platão o que se entendia por ciência não tem o mesmo sentido de hoje. Platão distingue três faculdades, cada uma com seu objeto próprio e nas quais se enquadram as modalidades do saber (se assim podem ser chamadas): conhecimento que corresponde ao ser, ignorância que corresponde ao não-ser e a via intermediária que é opinião que corresponde à aparência das coisas sensíveis.

Em Platão, só a dialética é ciência, pois ciência para ele é recordação das Formas em si, e nenhuma outra ciência tem por objeto as formas em si, fora do método dialético. A matemática não é ciência, porque ciência em Platão é recordação e recordação das Formas, como os objetos matemáticos não são perfeitos em si, não são Formas. A matemática enquadra-se como entendimento, que é algo intermediário entre a opinião e a razão. A matemática não é desprezada por Platão, mesmo não sendo geradora de conhecimento, ela tem sua participação no processo cognitivo, pois empurra a alma para a verdade.

\section{REFERÊNCIAS}

GADAMER, Hans-Georg. Acerca do filosófico nas ciências e do científico na filosofia. In: A razão na época da Ciência. Rio de Janeiro: Edições Tempo Brasileiro, 1983. p 9-26

MACLARTY, Colin. Platonismo Matemático versus Recolher os Mortos: o que Sócrates ensina a Glauco.

PLATÃO. Diálogos: República. Tradução e notas de Carlos Alberto Nunes. - 1. ed. - São Paulo - SP: Abril Cultural, 1977.

Diálogos: O Banquete - Fédon - Sofista - Político. Seleção de textos de José Américo Motta Pessanha; traduções e notas de Jorge Paleikat e João Cruz Costa. - 1. ed. - São Paulo - SP: Abril Cultural, 1970.

Diálogos: Teeteto e Crátilo. Tradução e notas de Carlos Alberto Nunes. - 2. ed. - São Paulo - SP: Abril Cultural, 1979.

SANTOS, José Trindade. Fédon, de Platão. Apartado: Alda, 1998

José Trindade. A função da alma na percepção, nos diálogos platónicos. Lisboa, Brasília e S. Paulo 2004.

DIALEKTIKÉ, v. 1, novembro 2014, p. 89-96

Artigo submetido em setembro/2014 e aceito em outubro/2014 